TITLE:

\title{
Evaluation of the photolysis of pharmaceuticals within a river by 2 year field observations and toxicity changes by sunlight.
}

\section{AUTHOR(S):}

Hanamoto, Seiya; Kawakami, Tsukasa; Nakada, Norihide; Yamashita, Naoyuki; Tanaka, Hiroaki

\section{CITATION:}

Hanamoto, Seiya ... [et al]. Evaluation of the photolysis of pharmaceuticals within a river by 2 year field observations and toxicity changes by sunlight.. Environmental science. Processes \& impacts 2014, 16(12): 2796-2803

\section{ISSUE DATE:}

2014-10-28

URL:

http://hdl.handle.net/2433/200195

\section{RIGHT:}

This journal is (c) The Royal Society of Chemistry 2014.; The full-text file will be made open to the public on 28 Oct 2015 in accordance with publisher's 'Terms and Conditions for Self-Archiving'.; This is not the published version. Please cite only the published version.; この論文は出版社版でありません。引用の際には出版社版をご確認ご利用ください。 


\section{Evaluation of the photolysis of pharmaceuticals within a river by 2-year \\ 2 field observations and toxicity changes by sunlight ${ }^{\dagger}$}

3 Seiya Hanamoto ${ }^{a}$, Tsukasa Kawakami ${ }^{a}$, Norihide Nakada ${ }^{a}$, Naoyuki Yamashita ${ }^{a}$ and Hiroaki

4 Tanaka $^{a *}$

\section{Abstract}

6 To improve the risk assessment of pharmaceuticals, it is helpful to know how rapidly they are removed from river water. Direct photolysis by sunlight could be an important process, but so far few studies have attempted to compare modeled with actual losses in a river. Therefore, we quantified natural attenuation by monitoring 56 pharmaceuticals and personal care products over 2 full years in a $2.6-\mathrm{km}$ stretch of an urban river. In addition, to screen photoproducts, we used the Microtox test with Vibrio fischeri to evaluate changes in the toxicity of two photolabile pharmaceuticals, ketoprofen and diclofenac, under sunlight. During transport along the river stretch, ketoprofen and the photolabile pharmaceutical furosemide were attenuated by median values of $77 \%$ and $39 \%$. The observed attenuation showed good agreement with photochemical attenuation estimated by a existing method at each sampling, suggesting that the method appeared to be effective for estimating the direct photolysis of the pharmaceuticals during river transport. The toxicity of diclofenac decreased under sunlight, while that of ketoprofen increased immediately after exposure (around 12 times in $\mathrm{EC}_{20}$ ) and remained high, indicating the existence of toxic and photostable photoproducts of ketoprofen. Therefore, ecological risks of photolabile pharmaceuticals may increase during river transport in some cases, indicating the necessity to incorporate their photoproducts into the estimation method.

\section{Introduction}

In recent years, numerous potentially hazardous chemicals such as pharmaceuticals and personal care products (PPCPs), ${ }^{1}$ endocrine-disrupting chemicals, ${ }^{2}$ perfluorinated compounds, ${ }^{3}$ fluorescent whitening agents, ${ }^{4}$ and nitrosamines ${ }^{5}$ have been detected in wastewaters. Once the chemicals enter the aquatic environment, they might be attenuated by physical, chemical, or biological factors. Because some of them are photolabile in sunlight (e.g., pharmaceuticals, ketoprofen; ${ }^{6}$ personal care products, triclosan; ${ }^{7}$ fluorescent whitening agents, distyryl biphenyl $;^{8}$ and nitrosamines, N-nitrosodimethylamine ${ }^{9}$ ), modeling their photochemical attenuation in the aquatic environment is important to estimating their concentrations and 
ecological risks.

Zepp et al. ${ }^{10}$ proposed an equation for estimating direct photolysis rate constants of chemicals in the aquatic environment. However, solar spectral distribution, an important parameter for estimating direct photolysis rate constants, cannot be measured everywhere on account of the high cost of its analysis. Therefore, measurements of bands of sunlight (e.g. UVA, UVB, and global radiation) are often substituted in the equation. ${ }^{6,7}$ Although we have corroborated the equation over several days, ${ }^{6}$ it has not hitherto been corroborated under field conditions over the long term. The solar spectral distribution on a horizontal surface was fluctuated during the year by solar altitude, atmospheric ozone content, and cloud cover. Therefore, it is important to test the practicality of substituting measurements of bands of sunlight for those of solar spectral distribution in estimating photon number absorbed by chemicals under solar spectral distributions during the year. In addition, since the quantum yields of chemicals (i.e., fraction of absorbed light that results in photoreaction) are often obtained as average values within the wavelengths of light absorption, ${ }^{6-9}$ it is also important to test the practicality of using them in the estimation under solar spectral distributions during the year. Furthermore, unknown parameters might be discovered by corroboration under field conditions during the year.

Until about 2005, most studies of the natural attenuation of chemicals were limited to the laboratory owing to difficulties in their isolation in the field. Since then, several studies have reported the natural attenuation of chemicals during river transport, ${ }^{6,11-22}$ including diurnal variation. ${ }^{6,21,22}$ However, no studies have measured seasonal variation of the natural attenuation throughout the year. Therefore, the natural attenuation should be clarified under field conditions over at least a year, and the method for estimating direct photolysis should be corroborated under the same conditions.

In addition, the method is desirable to incorporate the production rates and persistence of photoproducts in the aquatic environment in order not to overlook the potential risks of breakdown products, and be corroborated with them too. Because many photoproducts are often produced from a single chemical, the photoproducts should be screened by comparing the toxicity of each with the total. Since few of the photoproducts exist as purified reagents, the total toxicity should be estimated first by measuring the change in toxicity under sunlight. We previously identified three photolabile pharmaceuticals (i.e., ketoprofen, furosemide, and diclofenac) which showed appreciable attenuation during river transport. ${ }^{6}$ Although several photoproducts of ketoprofen have been identified, ${ }^{23-26}$ changes in its ecotoxicity under sunlight have been little studied. Wang et al. ${ }^{27}$ reported that the ecotoxicity of ketoprofen 
66

67

68

69

increased but then disappeared under sunlight, in contradiction of reports that photoproducts of ketoprofen are stable. ${ }^{24,25}$ The reason for this contradiction should be clarified. Although the toxicity of diclofenac evaluated by inhibition of algal reproduction increased under sunlight, ${ }^{28}$ there is no information on other organisms. There is no information on changes in the toxicity of furosemide under sunlight, which could be due to its low toxicity.

We quantified natural attenuation by monitoring 56 PPCPs over a full 2 years in an urban river in the city of Kyoto, Japan, and estimated attenuation caused by direct photolysis using the method proposed in our previous study. ${ }^{6}$ The method was corroborated under field conditions using ketoprofen and furosemide. We also used the Microtox test with Vibrio fischeri in evaluating changes in the toxicity of ketoprofen and diclofenac under sunlight.

\section{Methods}

\subsection{Site Descriptions}

Field surveys were conducted along a 2.6-km stretch of the Nishitakase River (Figure 1), in the city of Kyoto. The UV intensity in Kyoto at midday is UVA $=37.6 \pm 10.6 \mathrm{~W} / \mathrm{m}^{2}, \mathrm{UVB}=$ $0.85 \pm 0.23 \mathrm{~W} / \mathrm{m}^{2}$ in August, and UVA $=14.9 \pm 4.4 \mathrm{~W} / \mathrm{m}^{2}, \mathrm{UVB}=0.22 \pm 0.06 \mathrm{~W} / \mathrm{m}^{2}$ in December. The average river depth along the stretch is $0.5 \mathrm{~m}$, and the decadic absorption coefficient of surface water at Tenjin Bridge at $340 \mathrm{~nm}$ averages $2.1 \mathrm{~m}^{-1}$. The riverbed consists mainly of gravel, sand and concrete. There is little vegetation along the river. The stretch receives water from two wastewater treatment plants (WWTPs; sites 1, 2), and travel times from site 1 to 3 and from site 2 to 3 averaged $2.9 \mathrm{~h}$ and $1.0 \mathrm{~h}$, respectively. Information on these WWTPs and the quality of their effluents is summarized in the Supporting Information (SI) Tables S1 and S2. Because there is no additional significant inflow in the stretch or upstream of WWTP K (site 1), during dry weather the river water consists solely of treated wastewater. WWTP T (site 2) is the major source of most of the target PPCPs in the stretch (SI Figure S1), mainly because WWTP T uses chlorination, whereas WWTP K uses ozonation as disinfection. ${ }^{29}$ 


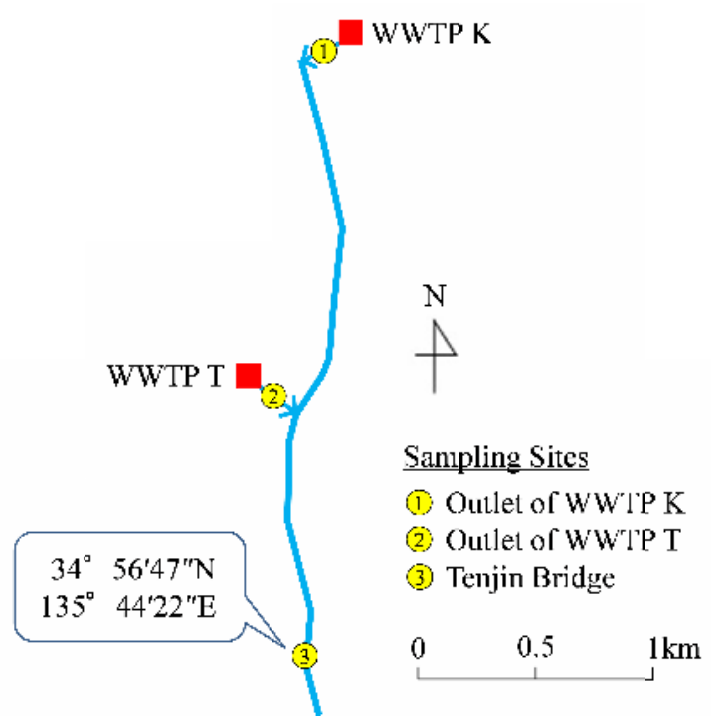

Figure 1. Locations of the wastewater treatment plants and sampling sites on the Nishitakase River.

\subsection{Field Study}

Surface water samples were collected at 3 sites (Figure 1) one to four times a month between October 2009 and September 2011, yielding total of 49 samplings. The samples were collected by grab in a stainless steel bucket around midday. Considering the travel time, samples at site 3 were collected around $1 \mathrm{~h}$ after collecting samples at site 2 , the major source of most of the PPCPs (SI Figure S1). The samples were stored in brown glass bottles with ascorbic acid at $1.0 \mathrm{~g} / \mathrm{L}$ in darkness and taken to the laboratory. The 56 selected PPCPs in the dissolved phase were concentrated by solid-phase extraction, measured by ultra-performance liquid chromatography / tandem mass spectrometry (LC-MS/MS), and quantified by the alternative surrogate method or the absolute standard method. ${ }^{30}$

We used the mass balance approach to estimate the attenuation of the PPCPs. The amount of a compound still remaining at the most downstream site (site 3) relative to the total inflow from the WWTPs (site 1,2) is defined as mass recovery (eq 1). The ratio of the flow at site $1\left(Q_{1}\right)$ to that at site $2\left(Q_{2}\right)$ was estimated for each sampling from the mass balance of carbamazepine (eq 2), which is persistent in aquatic environments ${ }^{31-33}$ and whose diurnal variation in mass loading discharged from WWTP T is low. ${ }^{6}$

$$
\begin{gathered}
r=\frac{\left(Q_{1}+Q_{2}\right) C_{3}}{Q_{1} C_{1}+Q_{2} C_{2}} \times 100=\frac{(\beta+1) C_{3}}{\beta C_{1}+C_{2}} \times 100(1) \\
\beta\left(C_{c}\right)_{1}+\left(C_{c}\right)_{2}=(\beta+1)\left(C_{c}\right)_{3}(2)
\end{gathered}
$$

where $r=$ mass recovery of a compound (\%), $C_{i}=$ concentration of the compound at site $i$ (ng/L), $Q_{i}=$ flow at site $i\left(\mathrm{~m}^{3} / \mathrm{s}\right), \beta=$ ratio of flow at site $1\left(Q_{1}\right)$ to that at site $2\left(Q_{2}\right)(-)$, and 
$115\left(C_{\mathrm{c}}\right)_{i}=$ concentration of carbamazepine, a persistent pharmaceutical, at site $i(\mathrm{ng} / \mathrm{L})$.

\section{2.3. Estimation of Attenuation Caused by Direct Photolysis in the River}

117 The attenuation of PPCPs in the stretch caused by direct photolysis was estimated for each 118 sampling using the equation proposed in our previous study, ${ }^{6}$ and evaluated as mass recovery.

119 The stretch was divided into two reaches at WWTP T. The parameters were set as follows

120 (Table 1). Monitoring data in the city of Kyoto at each sampling time ${ }^{34,35}$ were substituted for 121 sunlight intensity in the UVB and UVA regions ( $U V B, U V A)$. If the intensities at Kyoto were 122 not available, those of Otsu, the city next to Kyoto, were substituted for them. Theoretical 123 values at midday at latitude $40^{\circ} \mathrm{N}^{10}$ were substituted for annual average values of sunlight intensity in the UVB and UVA regions $\left(U V B_{t}, U V A_{t}\right)$ and the spectrum of sunlight $\left(L_{\lambda t}\right)$. Since most UVA and UVB reaching Earth's surface is sky radiation, constants for sky radiation ${ }^{10}$ were substituted for the fraction of sunlight reflected at the surface of the water body $\left(R_{\mathrm{UVB}}\right.$, $\left.R_{\mathrm{UVA}}\right)$ and for the path length of sunlight in the water $\left(l_{i}\right)$. The fraction of sunlight shaded by

128 aquatic plants ( $\left.B_{\mathrm{UVB}}, B_{\mathrm{UVA}}\right)$ was set to 0 , because little vegetation covered the water surface.

129 To clarify the light penetration in the river, we collected water samples 12 times during the 130 sampling period at Tenjin Bridge, and measured the absorptivity between 290 and $500 \mathrm{~nm}$ 131 with a UV-Vis spectrophotometer (UV-2500PC, Shimadzu, Kyoto, Japan). Because the absorptivities at $<380 \mathrm{~nm}$, which is the main region of absorbance for most of the PPCPs, ${ }^{6} \mathrm{did}$ not differ significantly among the 12 sampling days (coefficients of variation $[\mathrm{CVs}]<20 \%$ ),

134 the mean values at each wavelength were substituted for the absorption coefficient of the

135 water body $\left(\alpha_{\lambda i}\right)$. Travel time and depth of water were monitored three times during the 136 sampling period around the study area. Because flow rate at Tenjin Bridge did not differ 137 significantly among the 49 samplings $(\mathrm{CV}<20 \%),{ }^{36}$ the mean values were substituted for the 138 travel time $\left(t_{i}\right)$ and depth of water $\left(D_{i}\right)$. Measurements at each sampling were substituted for mass loadings of the PPCPs at sources $\left(L_{0 i}\right)$. Experimental values obtained in our previous

140 study $^{6}$ were substituted for quantum yields $(\varphi)$ and molar absorption coefficients $\left(\varepsilon_{\lambda}\right)$ of the

141 PPCPs. For the PPCPs whose average degradation was $<20 \%$ during the photolysis

142 experiment conducted in our previous study, ${ }^{6}$ quantum yields were set to 0. 


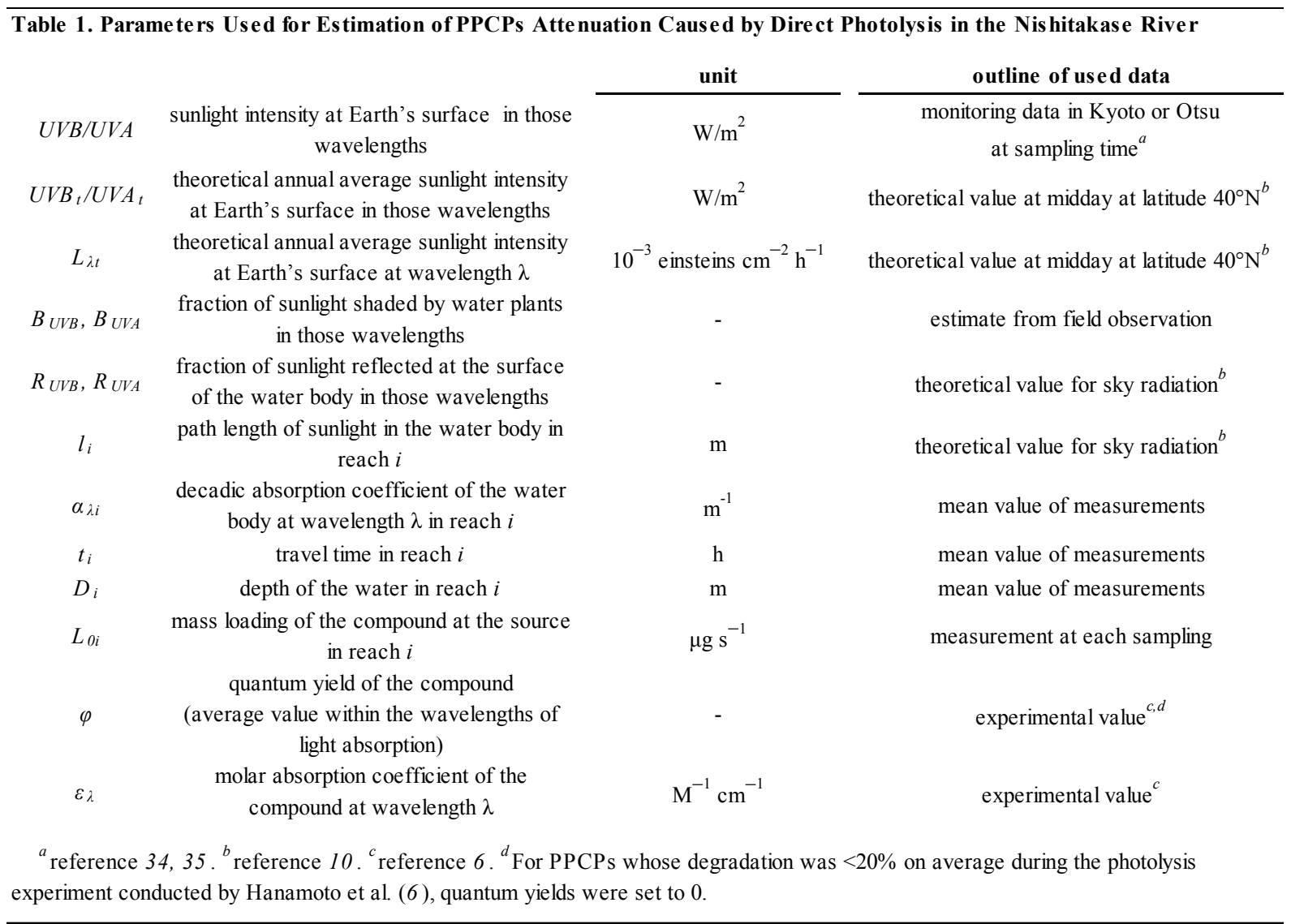

143

\subsection{Toxicity Change of Ketoprofen and Diclofenac under Sunlight}

Ultrapure water was autoclaved and the $\mathrm{pH}$ was adjusted to 6.9 with phosphate buffer (20 $\mathrm{mM}$ ). Ketoprofen and diclofenac were added to give an initial concentration of $50 \mathrm{mg} / \mathrm{L}$ and $20 \mathrm{mg} / \mathrm{L}$, respectively. The solutions $(100 \mathrm{ml})$ were poured into $100 \mathrm{ml}$ beaker made of borosilicate glass and exposed to artificial sunlight (Ultra-Vitalux, $300 \mathrm{~W}$, Osram, Munich, Germany) from directly above. The radiation intensity was set at around $1600 \mathrm{~W} / \mathrm{m}^{2}$. The water temperature was maintained at $20 \pm 1^{\circ} \mathrm{C}$ during the experiment by a water circulator (CTP-300, Tokyo Rikakikai Co, Ltd., Tokyo, Japan). A 2-ml aliquot was collected from the solution containing ketoprofen at $0,1,2,3,4,5,7,10,15,20,30,60,120,180,240$ and 300 min, and from the solution containing diclofenac at 0, 15, 30, 60, 120, 180, 240 and $300 \mathrm{~min}$ after the start of sunlight exposure. Absorbance (1-cm cell, $490 \mathrm{~nm}$ ) was 0 at $0 \mathrm{~min}$ in both solutions, but 0.005 in the ketoprofen solution and 0.049 in the diclofenac solution at $300 \mathrm{~min}$, which would be due to their photoproducts. The $\mathrm{pH}$ did not change during the exposure.

Changes in concentrations in darkness were negligible (data not shown).

We measured the concentrations of the selected pharmaceuticals in all samples and the Microtox acute toxicity of the samples. In addition, we made dilution series of the samples collected from the ketoprofen solution at 0 and $300 \mathrm{~min}$, and measured their Microtox acute 
161 toxicities. The Microtox test was performed with the luminescent marine bacterium Vibrio

162 fischeri on a model 500 analyzer (AZUR Environmental, Fairfax, CA, USA) in accordance 163 with the Microtox ${ }^{\circledR}$ Acute Toxicity Basic Test Procedures. ${ }^{37}$ Phosphate-buffered saline (PBS;

$1642 \% \mathrm{NaCl}, 20 \mathrm{mM}$ phosphate, $\mathrm{pH} 7$ ) was added to the samples to control salinity and $\mathrm{pH}$.

165 Decreases in bioluminescence were measured in duplicate after 15-min exposure at $15 \pm$

$1660.5^{\circ} \mathrm{C}$. Toxicities are expressed as the percentage inhibition of luminescence in the test

167 solutions relative to a control solution (i.e., solution without the addition of sample).

\section{3. Results and Discussion}

\section{3.1.Natural Attenuation of PPCPs and Effect of Direct Photolysis in the River}

170 We detected 28 PPCPs consistently at more than one of the WWTPs (SI Table S3), and the

171 CVs of mass loadings of 16 of them at WWTP T (site 2) within a day were low (median <

172 20\%) in dry weather. ${ }^{6}$ These low CVs indicate that diurnal variations in mass loadings

173 discharged at WWTP T would not produce substantial error in estimates of the attenuation of

174 PPCPs in the river stretch. Because WWTP K is a minor source of the 16 PPCPs in the stretch

175 (SI Figure S1), diurnal variations in mass loadings discharged at WWTP K also would not

176 produce substantial error in the estimation. The mass recoveries observed in the field and

177 estimated by considering only direct photolysis as an attenuation factor are shown in Figure 2

178 for 15 of the PPCPs (carbamazepine was excluded owing to its use in calculating mass

179 recovery). Mass recoveries of crotamiton, sulpiride and several others observed in the field

180 were around $100 \%$, indicating no appreciable attenuation. On the other hand, the median mass

181 recoveries of ketoprofen and furosemide were $<70 \%$, indicating appreciable attenuation along

182 the river stretch. Comparison of the mass recoveries with that estimated by considering only

183 direct photolysis as an attenuation factor suggested that the attenuation of the PPCPs was due

184 mainly to direct photolysis. This is not consistent with our finding that adsorption to

185 sediments is responsible for the attenuation of disopyramide, trimethoprim, roxithromycin,

186 and ofloxacin in the Katsura River, ${ }^{6}$ which would be due to differences between components

187 of the rivers such as fine sediment, natural water from upstream, and water quality (e.g., $\mathrm{pH}$,

188 water temperature, and ionic strength). 


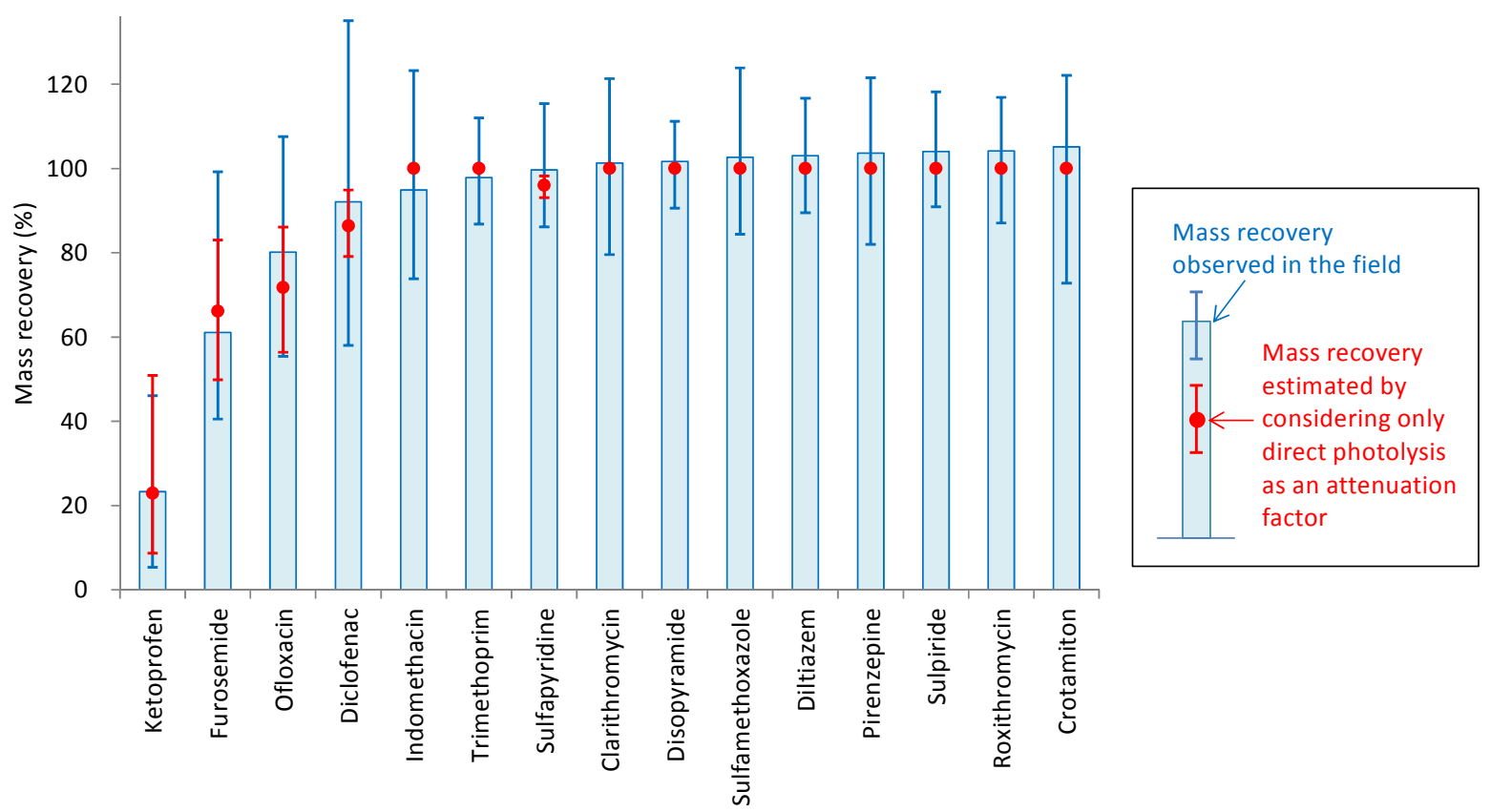

190 Figure 2. Mass recoveries of 15 PPCPs at Tenjin Bridge (site 3) relative to the total inflow

191 from the sources ( sites 1,2) observed in the field and estimated by considering only direct

192 photolysis as an attenuation factor. Field surveys were conducted along a 2.6-km stretch of

193 the effluent-dominated river over 2 full years $(n=49)$; vertical bars and plots denote 50th

194 percentile; error bars denote 10th and 90th percentiles.

\subsection{Corroboration of Method for Estimating Direct Photolysis in River under Field}

\section{Conditions over the Long Term}

197 For corroborating the method for estimating direct photolysis, ${ }^{6}$ target chemicals should be insensitive to attenuation factors other than direct photolysis in order to reveal attenuation attributable solely to direct photolysis. Because ketoprofen and furosemide are insensitive to attenuation factors other than direct photolysis (see SI and our previous study ${ }^{6}$ ) and their photodegradability is little affected by $\mathrm{pH}$ and water temperature (SI Table S4), we used them to corroborate the method. The mass recoveries estimated by considering only direct photolysis as an attenuation factor agreed closely with those observed in the field at each sampling, especially for ketoprofen (Figure 3). The correlation coefficient $\left(R^{2}\right)$ and slope of the regression line of furosemide are lower than those of ketoprofen, as the experimental error of the observed mass recovery became larger because of its lesser attenuation. Thus, the equation appears to be effective for estimating the direct photolysis of the pharmaceuticals during river transport under field conditions over the long term. Therefore, it would be reasonable to substitute measurements of bands of sunlight for those of solar spectral distribution and use average values within the wavelengths of light absorption for quantum 
211 yields in the estimation for the pharmaceuticals. Although the result is affected somewhat by 212 the absorption spectra and wavelength dependency of the quantum yield of chemicals,

213 ketoprofen and furosemide represent the absorption spectra of photolabile PPCPs shown in 214 our previous study except for those that absorb both UV and Vis. ${ }^{6}$ These results have

215 considerably enhanced the practical utility of the method for estimating direct photolysis of 216 chemicals in the aquatic environment. 

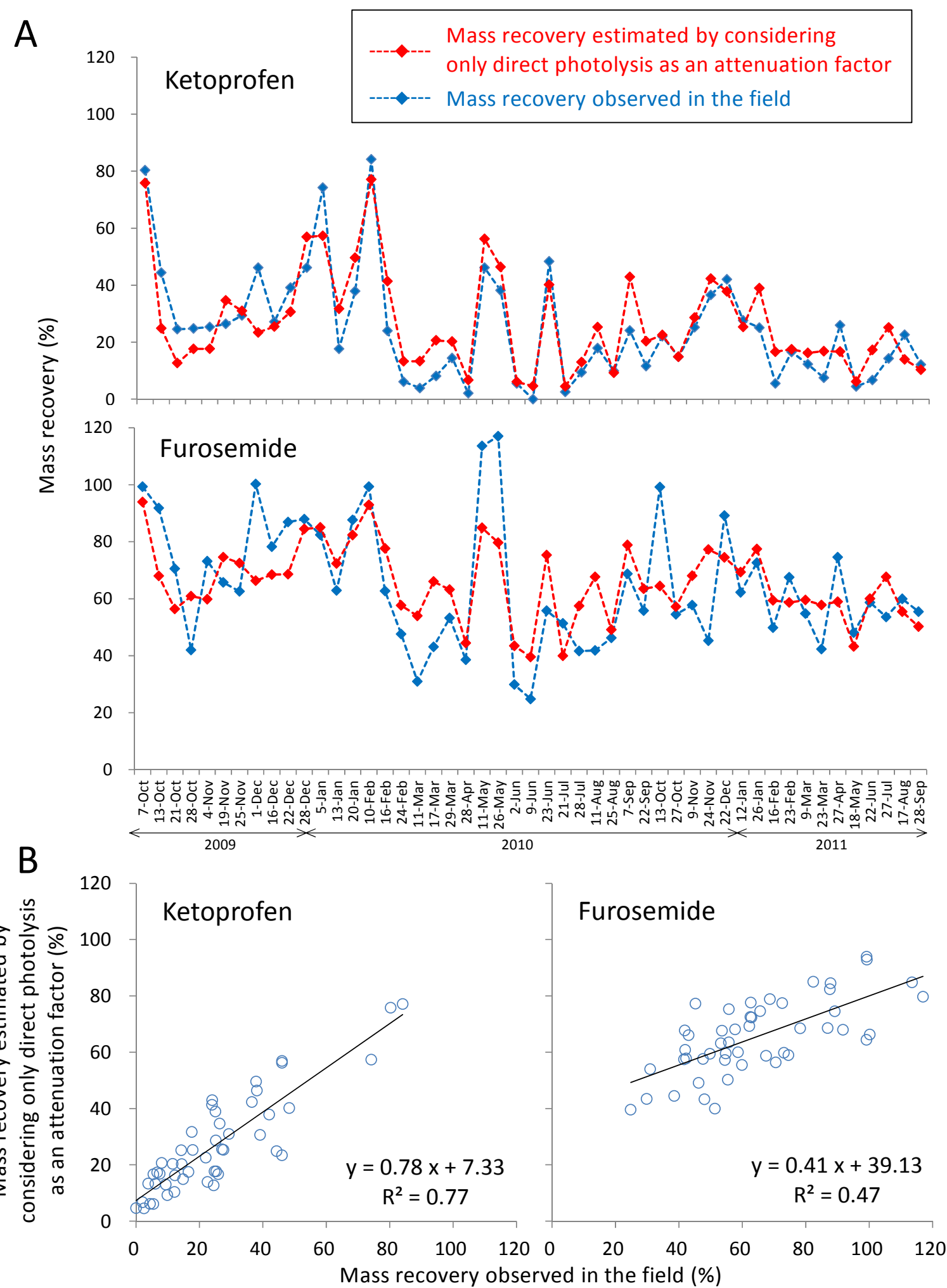

218 Figure 3. Comparison of mass recoveries of two pharmaceuticals observed in the field and

219 estimated by considering only direct photolysis as an attenuation factor, (A) by sampling date 220 and (B) by correlation. Estimated mass recoveries were obtained using the equation proposed 221 by Hanamoto et al. ${ }^{6}$ 


\subsection{Toxicity Change of Pharmaceuticals under Sunlight}

223 Photolysis of diclofenac did not appear to release by-products which were toxic to Vibrio

224 fischeri (Fig. 4), although a previous study indicated that photoproducts were toxic to algae. ${ }^{28}$

225 The toxicity of ketoprofen solution increased immediately on exposure and remained steady

226 thereafter, indicating the existence of toxic and photostable photoproducts of ketoprofen. The

227 toxicity of ketoprofen solution collected at $300 \mathrm{~min}$ exposure, which would represent the total

228 toxicity of its photostable photoproducts, is around 12 times that before exposure when

229 expressed as $\mathrm{EC}_{20}$ (i.e. effective concentration at $20 \%$ inhibition). This result is consistent

230 with previous reports that photoproducts of ketoprofen are stable, ${ }^{24,25}$ but not with the report

231 that the Microtox acute toxicity of ketoprofen measured with Vibrio fischeri increased but

232 then disappeared under sunlight. ${ }^{27}$ The radiation intensity in the latter study was lower than

233 that in this study, but that difference cannot explain the disappearance of the toxicity shown in

234 that study. The discrepancy could be attributed to the much lower initial concentration of

235 ketoprofen in the latter study: because the initial concentration of ketoprofen was only $2 \%$ of

236 that here, the toxicity of its photostable photoproducts would be under the detection limit of

237 the Microtox test in the latter study. ${ }^{27}$ The early toxicity in the latter study would be

238 attributable to photolabile photoproducts of ketoprofen, which would be much more toxic

239 than the photostable photoproducts. In this study, the appearance and disappearance of

240 toxicity due to the photolabile photoproducts would be included in the early sharp increase in 241 toxicity. 

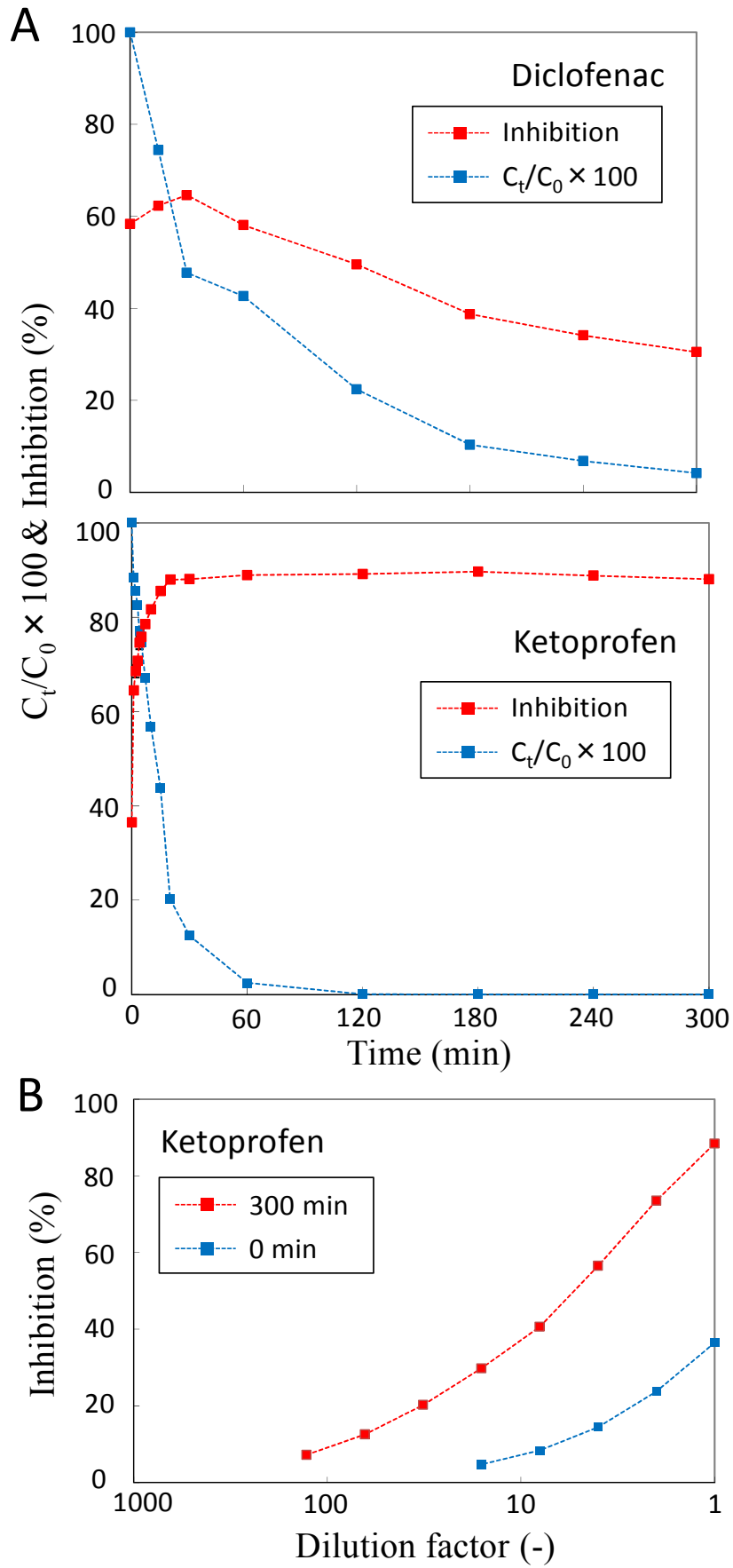

243 Figure 4. (A) Change of concentration ratio $\left(C_{t} / C_{0}\right)$ and Microtox acute toxicities (inhibition)

244 of two pharmaceuticals under sunlight. (B) Microtox acute toxicities (inhibition) of dilution

245 series of samples collected from ketoprofen solution at 0 and $300 \mathrm{~min}$ after the start of

246 sunlight exposure. Mean of duplicate was shown for the inhibition.

4. Conclusions

248 In this study we quantified natural attenuation for 15 PPCPs over a full 2 years in an urban

249 river, and 2 photolabile pharmaceuticals (ketoprofen and furosemide) showed appreciable 
250

251

252

253

254

255

256

257

258

259

260

261

262

263

264

265

266

267

attenuation along the river stretch. The observed attenuation showed good agreement with photochemical attenuation estimated by existing method at each sampling for the 2 photolabile pharmaceuticals, suggesting that the method appeared to be effective for estimating the direct photolysis of the pharmaceuticals during river transport. The result has considerably enhanced the practical utility of the method for estimating direct photolysis of chemicals in the aquatic environment.

The total toxicity of diclofenac and its photoproducts to Vibrio fischeri decreased under sunlight, while that of ketoprofen increased immediately after exposure and remained high, indicating the existence of toxic and photostable photoproducts of ketoprofen. Therefore, ecological risks of photolabile pharmaceuticals may increase during river transport in some cases, indicating the necessity to incorporate their photoproducts into the estimation method.

In our future work, toxicity of each photoproduct should be quantified and compared with the total to screen the photoproducts. The production rates and persistence of the screened photoproducts in the aquatic environment should be incorporated into the method for estimating direct photolysis rate constants of chemicals, and the method should be corroborated using their measured aquatic concentrations.

\section{Acknowledgments}

We thank Prof. Konami (Kyoto Women's University), Dr. Hayakawa (Lake Biwa Environmental Research Institute), and the staff at Kyoto City Waterworks Bureau for providing the meteorological and hydrological data. We acknowledge the Japan Science and Technology Agency (JST) and the Japan Society for the Promotion of Science (JSPS) for funding.

\section{Notes and references}

${ }^{a}$ Research Center for Environmental Quality Management, Kyoto University, Japan, Graduate School of Engineering, Kyoto University, 1-2 Yumihama, Otsu, Shiga 520-0811, Japan

† Electronic Supplementary Information (ESI) available: [Details of WWTPs; detection, concentrations, and source distributions of PPCPs along the river stretch; effects of water temperature and $\mathrm{pH}$ on direct photolysis; indirect photolysis, and biodegradation; and other attenuation factors]. See DOI: 10.1039/b000000x/

(1) Nakada, N.; Tanishima, T.; Shinohara, H.; Kiri, K.; Takada, H. Pharmaceutical chemicals and endocrine disrupters in municipal wastewater in Tokyo and their removal during 
activated sludge treatment Water Res. 2006, 40, 3297-3303.

(2) Barber, L. B.; Brown, G. K.; Zaugg, S. D. Potential endocrine disrupting organic chemicals in treated municipal wastewater and river water. In Analysis of Environmental Endocrine Disruptors; Keith, L. H., Jones-Lepp, T. L., Needham, L. L., Eds.; ACS Symposium Series 747; American Chemical Society: Washington, DC, 2000; pp 97-123.

(3) Kim, S.-K.; Im, J.-K.; Kang, Y.-M.; Jung, S.-Y.; Kho, Y. L.; Zoh, K.-D. Wastewater treatment plants (WWTPs)-derived national discharge loads of perfluorinated compounds (PFCs). J. Hazard. Mater. 2012, 201-202, 82-91.

(4) Poiger, T.; Field, J. A.; Field, T. M.; Giger, W. Occurrence of fluorescent whitening agents in sewage and river water determined by solid-phase extraction and highperformance liquid chromatography. Environ. Sci. Technol. 1996, 30 (7), 2220-2226.

(5) Yoon, S.; Nakada, N.; Tanaka, H. Occurrence and removal of NDMA and NDMA formation potential in wastewater treatment plants. J. Hazard. Mater. 2011, 190, 897902

(6) Hanamoto, S.; Nakada, N.; Yamashita, N.; Tanaka, H. Modeling the photochemical attenuation of down-the-drain chemicals during river transport by stochastic methods and field measurements of pharmaceuticals and personal care products. Environ. Sci. Technol. 2013, 47, 13571-13577.

(7) Tixier, C.; Singer, H. P.; Canonica, S.; Müller, S. R. Phototransformation of triclosan in surface waters: a relevant elimination process for this widely used biocide-laboratory studies, field measurements, and modeling. Environ. Sci. Technol. 2002, 36 (16), $3482-3489$.

(8) Kramer, J. B.; Canonica, S.; Hoigné, J.; Kaschig, J. Degradation of fluorescent whitening agents in sunlit natural waters. Environ. Sci. Technol. 1996, 30 (7), 2227-2234.

(9) Plumlee, M. H.; Reinhard, M. Photochemical attenuation of N-nitrosodimethylamine (NDMA) and other nitrosamines in surface water. Environ. Sci. Technol. 2007, 41 (17), 6170-6176.

(10) Zepp, R.; Cline, D. Rates of direct photolysis in aquatic environment. Environ. Sci. Technol. 1977, 11 (4), 359-366.

(11) Lin, A.; Plumlee, M. H.; Reinhard, M. Attenuation of pharmaceuticals and alkylphenol polyethoxylate metabolites during river transport: Photochemical and biological transformation. Environ. Toxicol. Chem. 2006, 25 (6), 1458-1464.

(12) Kunkel, U.; Radke, M. Reactive tracer test to evaluate the fate of pharmaceuticals in rivers. Environ. Sci. Technol. 2011, 45, 6296-6302. 
(13) Kunkel, U.; Radke, M. Fate of pharmaceuticals in rivers: deriving a benchmark dataset at favorable attenuation conditions. Water Res 2012, 46, 5551-65.

(14) Radke, M.; Ulrich, H.; Wurm, C.; Kunkel, U. Dynamics and attenuation of acidic pharmaceuticals along a river stretch. Environ. Sci. Technol. 2010, 44, 2968-2974.

(15) Writer, J. H.; Ryan, J. N.; Keefe, S. H.; Barber, L. B. Fate of 4-nonylphenol and 17ßestradiol in the Redwood River of Minnesota. Environ. Sci. Technol. 2012, 46, 860-868.

(16) Barber, L.B.; Keefe, S.H.; Brown, G.K.; Furlong, E.T.; Gray, J.L.; Kolpin D.W.; Meyer, M.T.; Sandstrom M.W.; Zaugg, S.D. Persistence and potential effects of complex organic contaminant mixtures in wastewater-impacted streams. Environ. Sci. Technol. 2013, 47 (5), 2177-2188

(17) Osorio, V.; Marce, R.; Perez, S.; Ginebreda, A.; Cortina, J.L.; Barcelo, D. Occurrence and modeling of pharmaceuticals on a sewage-impacted Mediterranean river and their dynamics under different hydrological conditions. Sci. Total Environ. 2012, 440, 3-13.

(18) Fono, L. J.; Kolodziej, E. P.; Sedlak, D. L. Attenuation of wastewater-derived contaminants in an effluent-dominated river. Environ. Sci. Technol. 2006, 40, 7257-7262.

(19) Gurr, C. J.; Reinhard, M. Harnessing natural attenuation of pharmaceuticals and hormones in rivers. Environ. Sci. Technol. 2006, 40 (9), 2872-2876.

(20) Writer J.H.; Antweiler R.C.; Ferrer I., Ryan J.N.; Thurman E.M. In-stream attenuation of neuro-active pharmaceuticals and their metabolites. Environ. Sci. Technol. 2013, 47 (17), 9781-9790.

(21) Kari, F. G.; Giger, W. Modeling the photochemical degradation of ethylenediaminetetraacetate in the River Glatt. Environ. Sci. Technol. 1995, 29 (11), 2814-2827.

(22) Poiger, T.; Kari, F. G.; Giger, W. Fate of fluorescent whitening agents in the River Glatt. Environ. Sci. Technol. 1999, 33 (4), 533-539.

(23) Salgado, R.; Pereira, V.J.; Carvalho, G.; Soeiro, R.; Gaffney, V.; Almeida, C.; Vale Cardoso, V.; Ferreira, E.; Benoliel, M.J.; Ternes, T.A.; Oehmen, A.; Reis, M.A.M.; Noronha, J.P.; Photodegradation kinetics and transformation products of ketoprofen, diclofenac and atenolol in pure water and treated wastewater. J. Hazard. Mater. 2013, 244-245, 516-527.

(24) Kosjek, T.; Perko, S.; Heath, E.; Kralj, B.; Zigon, D. Application of complementary mass spectrometric techniques to the identification of ketoprofen phototransformation products. J. Mass Spectrom. 2011, 46, 391-401.

(25) Szabo R.K.; Megyeri C.S.; Illes E.; Gajda-Schrantz K.; Mazellier P.; Dombi A. 
Phototransformation of ibuprofen and ketoprofen in aqueous solutions. Chemosphere. 2011, 84 (11), 1658-1663.

(26) Matamoros, V.; Duhec, A.; Albaigés, J.; Bayona, J. M. Photodegradation of carbamazepine, ibuprofen, ketoprofen and $17 \alpha$-ethinylestradiol in fresh and seawater. Water Air Soil Pollut. 2008, 196, 161-168.

(27) Wang, X-H.; Lin, A. Y-C. Is the phototransformation of pharmaceuticals a natural purification process that decreases ecological and human health risks? Environ. Pollut. 2014, 186, 203-215.

(28) Schmitt-Jansen, M.; Bartels, P.; Adler, N.; Altenburger, R. Phytotoxicity assessment of diclofenac and its phototransformation products. Anal. Bioanal. Chem. 2006, 387 (4), 1389-1396.

(29) Kumar, V.; Hanamoto, S.; Johnson, A. C.; Yamashita, N.; Nakada, N.; Tanaka, H. Elevated risk from estrogens in the Yodo River basin (Japan) in winter and ozonation as a management option. Environ. Sci.: Processes Impacts 2014, in press

(30) Narumiya, M.; Nakada, N.; Yamashita, N.; Tanaka, H. Phase distribution and removal of pharmaceuticals and personal care products during anaerobic sludge digestion. J. Hazard. Mater. 2013, 260, 305-312

(31) Clara, M.; Strenn, B.; Kreuzinger, N. Carbamazepine as a possible anthropogenic marker in the aquatic environment: investigations on the behaviour of carbamazepine in wastewater treatment and during groundwater infiltration. Water Res. 2004, 38 (4), 947-954.

(32) Nakada, N.; Kiri, K.; Shinohara, H.; Harada, A.; Kuroda, K.; Takizawa, S.; Takada, H. Evaluation of pharmaceuticals and personal care products as water-soluble molecular markers of sewage. Environ. Sci. Technol. 2008, 42 (17), 6347-6353.

(33)Yamamoto, H.; Nakamura, Y.; Moriguchi, S.; Honda, Y.; Tamura, I.; Hirata, Y.; Hayashi, A.; Sekizawa, J. Persistence and partitioning of eight selected pharmaceuticals in the aquatic environment: laboratory photolysis, biodegradation, and sorption experiments. Water Res. 2009, 43 (2), 351-362.

(34) Project for monitoring sunlight intensity (in Japanese). Website: http://www.cs.kyotowu.ac.jp/ konami/climate/index.shtml (accessed January 30, 2014)

(35) Private letter from Lake Biwa Environmental Research Institute

(36) Private letter from Kyoto city waterworks bureau

(37) Microtox ${ }^{\circledR}$ Acute Toxicity Basic Test Procedures 